Original Research Paper

\title{
Intention to Use Mobile Learning in Higher Education Institutions: Review Paper
}

\author{
Ayad Shihan Izkair'1, Muhammad Modi Lakulu ${ }^{1}$, Ibtihal Hassan Mussa ${ }^{2}$ \\ ${ }^{1}$ Sultan Idris Education University, Malaysia. \\ ${ }^{2}$ Ministry of Education, Iraq.
}

Article History
Received:
04.10 .2020
Revised:
02.11 .2020
Accepted:
17.11 .2020
*Corresponding Author:
Muhammad Modi Lakulu
Email:
modi@fskik.upsi.edu.my

This is an open access article, licensed under: $\mathrm{CC}-\mathrm{BY}-\mathrm{SA}$

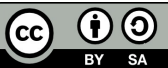

Abstract: Mobile learning is presently taking part in associate degree more and more important role within the instructional method, additionally as within the development of teaching and learning ways for higher education. The power to find out 'on the go- anytime, anywhere, is changing into more and more fashionable. The advantages offered by mobile learning are important. On the opposite hand, the implementation of mobile learning in educational activity relies on users' acceptance of technology. Acceptance and intention to use mobile learning may be a topic of growing interest within the field of education. The model of the unified theory of acceptance and use of technology (UTAUT) is planned and developed by researchers via a mixture of eight major theories in activity prediction. UTAUT is among the foremost fashionable and up to date model in information technology acceptance. This is review paper aiming to review UTAUT's previous studies of intention to use mobile learning. In conclusion, this research provides insight regarding the necessary factors for planning and designing an intention to use mobile learning model in higher education institutions.

Keyword: Mobile, Learning, Intention, UTAUT. 


\section{Introduction}

Mobile learning is characterised as a robust part of learning and education for facilitating learning experiences. With increased and speedy advancements of ICT (Information and Communication Technologies) technologies and mobile, varied innovative services and applications are being developed. Therefore, it's necessary to analyze the factors influencing the intention to use mobile learning among students of of higher education institutions [1].

Mobile learning may not be an alternative, however rather a necessity as a contemporary platform of learning within the future, in order that students are ready to keep up with this times and technology. Mobile learning has more crucial role within the development of teaching strategies of learning in higher education. By applying mobile technology, students will simply and quickly access and use learning resources anytime, anyplace [2].

Mobile learning has historically been additional powerfully developed among the fields of informal education. However, throughout the past few years, there's a growing interest in the mixing of those technologies in formal education. Among the key components required to successfully accomplish this integration method, is that the acceptance of mobile technologies by the teaching workers [3]. The increasing enlargement of mobile technology in society has become a reality [4]. In some countries, governments have achieved the specified level of satisfaction in giving mobile services to their voters though at the same time a number of the countries are still behind from the specified [5].

\section{The Advantages of Mobile Learning}

The main vital options of mobile learning are ubiquity and mobility. Ubiquity is that the access to technologies whenever and where the necessity arise, whereas mobility is learning on the go [6] [7]. Mobility isn't the sole feature of mobile learning approach, however the learning activity itself such decision-making, oral communication and interaction amongst instructors and students [8].

Furthermore, the most reasons for the ascent of mobile learning within the higher education are the rise range of mobile devices, low value of mobile services, fast development of mobile wireless technologies, capability enhancements of mobile devices, and multiple options (SMS, MMS, audio/video recording, photos capturing, knowledge storing, and web access). However, mobile learning continues to be within the early stages of development in education [7] [9], and for mobile learning to succeed, it's necessary to identify the factors influencing school students' acceptance of mobile learning [9].

Over the past few years, mobile technologies have expanded and consolidated in term of recognition as devices employed in daily activities. This fast expansion has seen accumulated interest from varied fields within the benefits derived from the combination of those resources. The conception of mobile learning (m-Learning) has emerged within the educational field reaching to build the foremost out of mobile devices as learning tools [3].

The educational application of those technologies promotes communication and students' autonomous learning, and it brings the teaching -learning method out of the schoolroom, therefore enabling learning anytime, anywhere. This breaks the barriers between formal and informal education, tight the event of latest method ways that contribute to gap up the faculties to the outside world, making bonds between colleges and families and between academics and students which permit teachers to guide the students' learning method within and outdoors the schoolroom [3] [10].

\section{Mobile Learning in Higher Educational Institutions}

Mobile learning has become a vital part of education and learning in universities. The most objective of "Information and Communications Technology" (ICT) is to beat the constraints of higher education services that embrace the restrictions of your time factors and placement considerations, because it offers these services anytime, anywhere. Access to desired info has been simplified creating it freed from limitations. The interactive setting between the instructors and students results has modified the normal plan of the classroom [1]. The combination of mobile learning methods in formal education establishments and processes continues to be in its primary development, providing initiatives are isolated, they seldom have any continuity and in some cases they are doing not yield the expected results [3].

Mobile learning permits the higher education institutions to satisfy the request of advanced digitalization of the internetworking that are display by the generation. The educational setting gets compatible with the needs of scholars in multiple contexts with fewer limitations of schedules and 
locations. The educational method gets simplified, and therefore the institutional reaching to students is exaggerated as compared to ancient learning practices. Access to the educational materials available any place and anytime through use of mobile learning within the setting [1].

Advancement in technology has driven a powerful demand for a lot of sophisticated teaching instruments like pc applications, videos, and instrumentation able to mix visual, audio and text. There's an increasing of population of educators that like utilizing instruments and teaching materials supported transmission in Asian country. Effectiveness of using multimedia for tutorial activities depends on the users, particularly students since multimedia has the ability to boost learning quality. Multimedia are often accustomed convey info to users effectively, through varied media channels, mobile communication and it's time economical. The educational that happens informally using mobile learning is additionally thought-about as learning. Mobile learning could be a viable mean to supply a spread of educational edges. These include access to tutorial and library info, supporting interactive and cooperative learning, expand student communication, and expand engagement with course material. In Japan, a research has incontestable that the distinctive characteristics of mobile technology will have a positive impact on knowledge acquisition and increase students' munity by extending learning to natural settings and mobile access to various resources [11].

\section{Unified Theory of Acceptance and Use of Technology}

The unified theory of acceptance and use of technology (UTAUT) model is planned and developed by researchers through the mixture of eight major theories in behavioral prediction. In reference to UTAUT it's comprised of four freelance variables: effort expectancy; social influences; facilitating conditions and performance expectancy [12]. These variables confirm a behavioral intention. Effort expectancy relates to the extent to that an individual perceives the system is simply adopted and used and almost like the ease of use construct as denoted in TAM. Performance expectancy is that the measuring of the degree which an individual perceives that victimization the system might assist to extend their performance level and this idea is comparable to the construct in TAM. Social influence may be a live of the degree to that an individual believes that others whom they care regarding are of the view that a specific system ought to be used.

Facilitating conditions is that the degree to that an individual perceives that there's a presence of organizational help to facilitate the utilization of the system. The two variables of effort expectancy and performance expectancy in UTAUT are similar concepts to the perceived ease of use and perceived usefulness in TAM. Social influence is likened to the issue of a 'subjective norm' in TAM2, associate extension of TAM. Facilitating conditions has the identical which means of compatibility construct from diffusion of innovation theory (DOI) in accordance with Venkatesh et al., [13].

UTAUT additionally takes into thought all of the moderating variables. These variables are: age; gender; voluntariness of use; and experience. In choosing UTAUT because the underlying theory, it's created on the idea of its comprehensiveness and its international approach. The UTAUT constructs are supported eight acceptance models of behavioral prediction (Venkatesh et al., 2003). UTAUT covers vital influencing factors of the acceptance of technology by users like technology factor that describes the characteristics of a technology and implementation setting factor that has organizational characteristics [13], [14].

\section{An Existing Research on Intention to Use of Mobile Learning}

Abu-Al-Aish \& Love [15] studied the factors that have an effect on university students' intentions to simply accept mobile learning. Based on UTAUT, this study proposes a model to identify the factors that influence acceptance of mobile learning in higher education and to analyse if previous expertise of mobile devices affects the acceptance of mobile learning. The results indicated that effort expectancy, performance expectancy, quality of service, influence of lecturers, and personal innovativeness were all significant factors that have an effect on intention to use of mobile learning . Previous expertise of mobile devices moderated the impact of those constructs on behavioral intention.

Milošević et al., [12] explained the factors that have an effect on the behavioral intention of students within the acquisition of mobile learning at the Technical College in Bor, University of Beograd (Serbia). The results provided valuable info concerning the admission and therefore the introduction of technology by each students and lecturers within the educational activity system in geographical area. It shows that the personal innovative capabilities and expected performance have the foremost vital influence on the behavioral intention of students earning mobile learning, which 
may result in improved performance and learning productivity in their studies. Effort expectancy is seen because the weakest links within the chain of the studied factors, as a result of students feel that they have to form extra effort to master mobile learning.

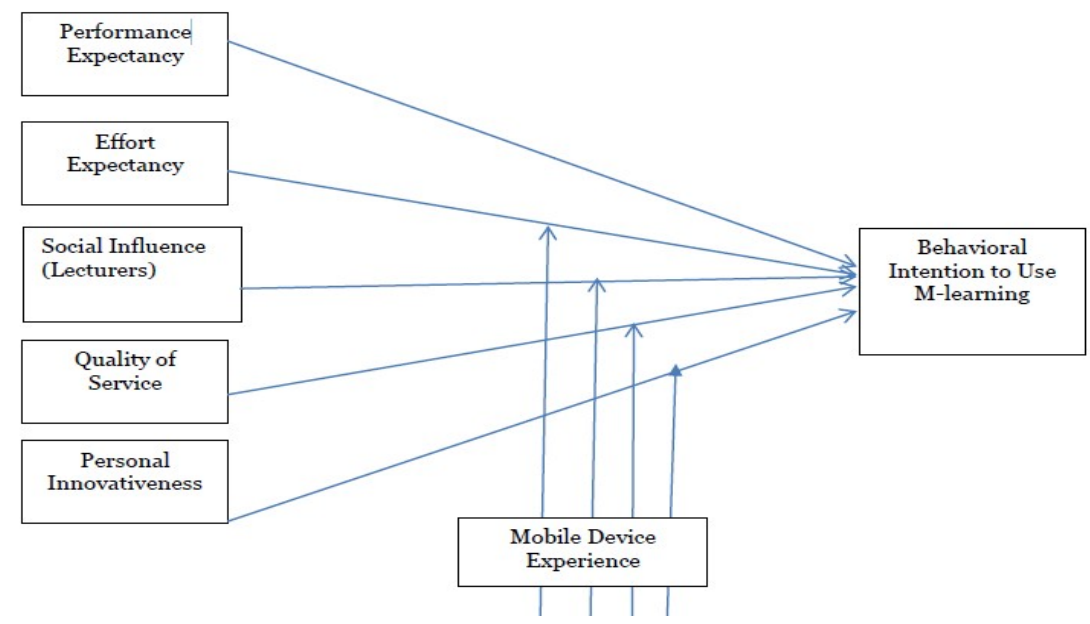

Figure 1. Intention to Use Mobile Learning Model [15]

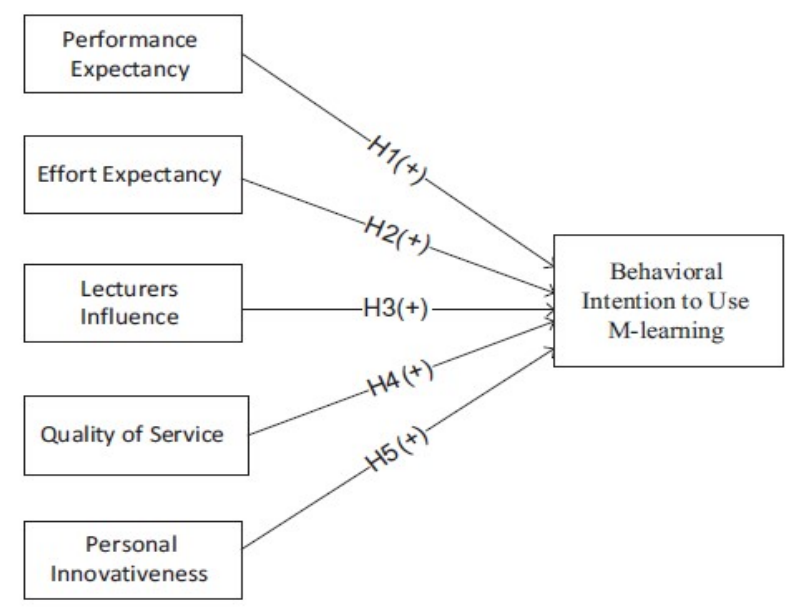

Figure 2. Behavioral Intention to Use Mobile Learning Model [12]

Huan et al. [15] analysis findings indicated that attainment value, performance expectancy, ubiquity, service quality, perceived enjoyment and self-management of learning significantly affected mobile learning adoption intention. The result obtained is that $87.9 \%$ of intention to adopt mobile learning is explained by the components within the extended UTAUT model. This study adds new knowledge and understanding to the mobile learning and technology acceptance theory. Decisionmakers in higher education will manipulate those factors to realize organization structure and education success in mobile learning adoption and implementation. 


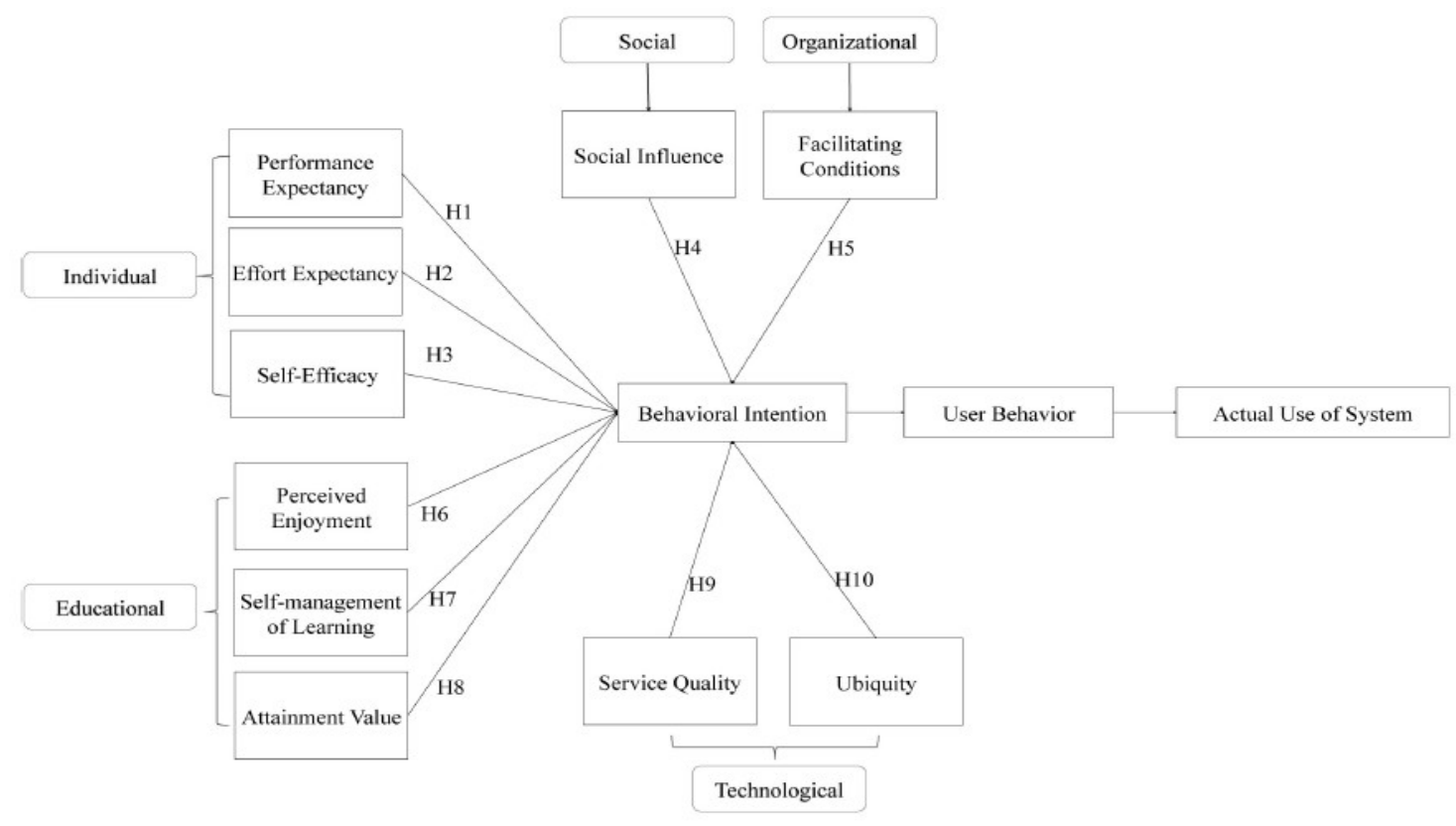

Figure 3. Behavioral Intention to Use Mobile Learning Model [16]

Mohammadi [17] study's aim is to explore the effects of perceived usefulness, perceived ease of use, perceived image, subjective norm, personal innovativeness, absorptive capacity, individual mobility, and self-efficacy on user intention and satisfaction, aboard the mediating impact of usability towards use of mobile learning in Asian nation. The results showed that "intention" and "user satisfaction" each foreseen the actual use of mobile learning. "Perceived image" and "Subjective norm" were found to be the foremost vital antecedents of user intention towards use of mobile learning. At last, "perceived usefulness" mediate the link between ease of use and user intention. The sample consisted of e-learning users of solely four public universities in Asian nation and private universities weren't studied.

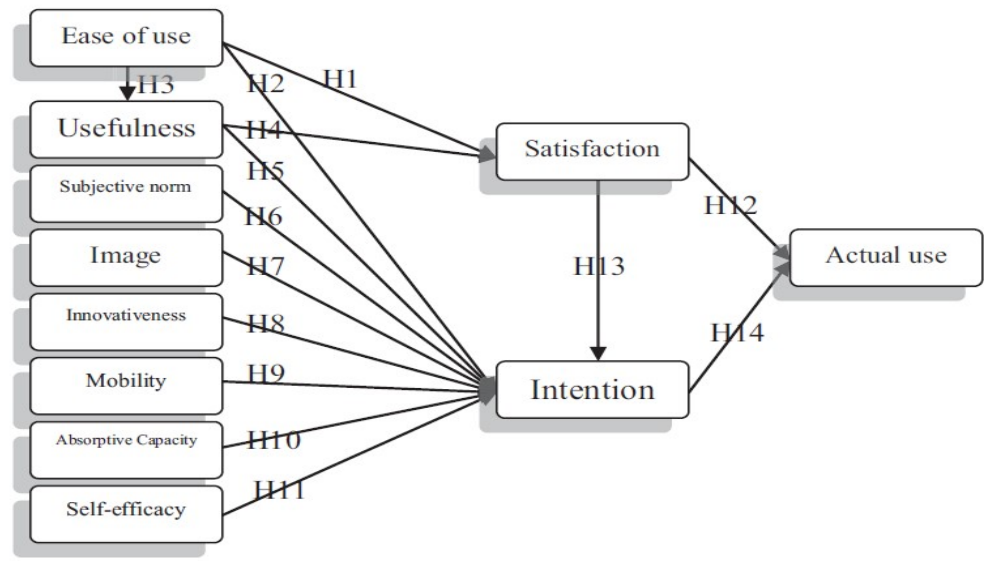

Figure 4. Intention to Use Mobile Learning Model [17]

Ali \& Arshad [12] tried to realize a far better understanding of the intention of scholars to require up mobile learning (m-learning) through an examination created on the underlying basis of UTAUT. Variety of things influenced the acceptance of mobile learning, such as: technology factors (including 
performance expectancy and effort expectancy); implementation setting factors (social influence and facilitating conditions); and individual factors (self-efficacy and self-regulation). The findings might enrich student expertise by giving colleges a tool to raised perceive the factors impacting students' ability to effectively utilize mobile learning; permitting schools to adapt their programs to boost learning by using mobile learning

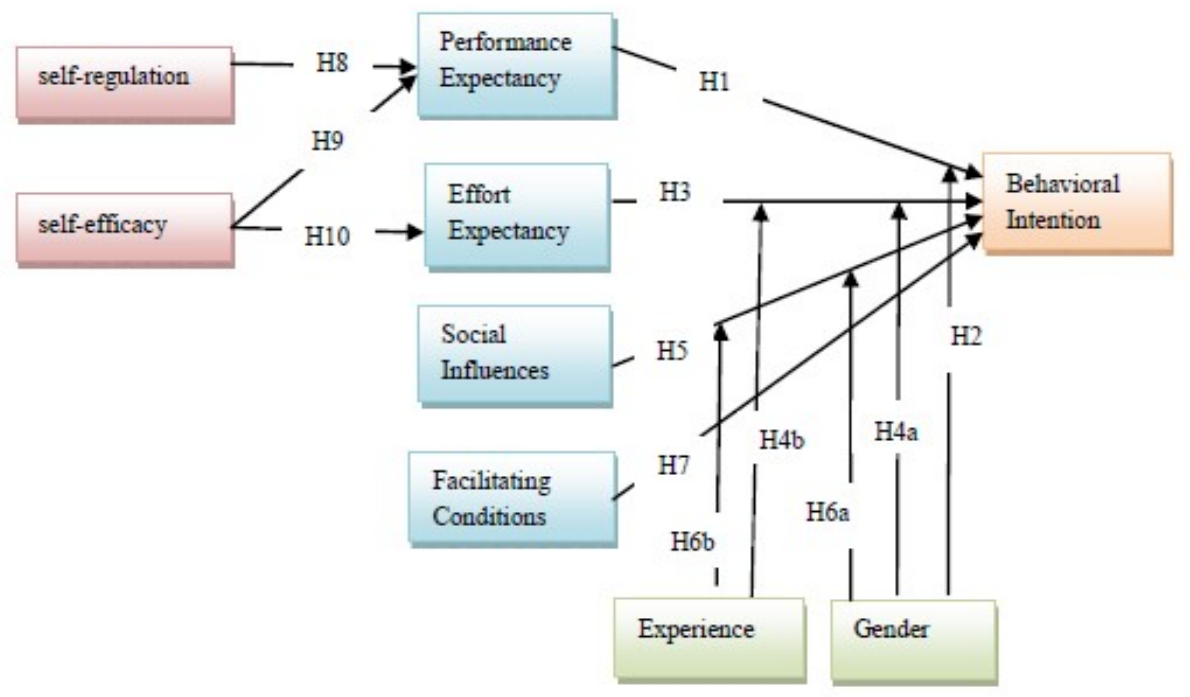

Figure 5. Behavioral Intention to Use Mobile Learning Model [12]

\section{Conclusion and Recommendation}

This study focused on reviewing previous studies for intention to use of mobile learning. UTAUT could be a common and up to date model in data technology acceptance, this study targeted on studies that depend upon UTAUT for acceptance and intention to use mobile learning. There are several factors that influenced intention to use mobile learning, and one study cannot cover all factors influencing this. It's necessary for university management to bear in mind and understand the factors within the studies mentioned during this analysis to be able to implement mobile learning in the universities. Moreover, the universities management must support the lecturers to attend the sufficient trainings to accumulate the specified skills and information to use and implement mobile learning. Additionally to that, the lecturers must inspire students regarding the advantages of mobile learning in their studies. Some students who are less innovative might have to be driven at the initial step of implementing mobile learning. Lecturers will promote students' acceptance of mobile learning by adding value to their ancient teaching strategies using mobile learning. However, they have to be familiar with this new technology and be able to be concerned within the implementation plans. Lastly, higher education institutions must develop strategic plans and supply guidelines on students' acceptance so as to incorporate all critical success factors for the sustainable deployment of mobile learning.

\section{References}

[1] A. Althunibat, "Determining the Factors Influencing Students' Intention to Use Mobile Learning in Jordan Higher Education," Computers in Human Behavior, vol. 52, pp. 65-71, 2015. doi: 10.1016/j.chb.2015.05.046.

[2] I. Milošević, D. Živković, D. Manasijević, and D. Nikolić, "The Effects of The Intended Behavior of Students in the Use of Mobile Learning," Computers in Human Behavior, vol. 52, pp. 207-215, 2015. doi: 10.1016/j.chb.2015.04.041.

[3] J. C. Sánchez-Prieto, S. Olmos-Migueláñez, and F. J. García-Peñalvo, "Informal tools in formal contexts": Development of a model To Assess the Acceptance of Mobile Technologies among 
Teachers," Computers in Human Behavior, vol. 55, pp. 519-528, 2015. doi: 10.1016/ j.chb.2015.07.002.

[4] L. Briz-Ponce, A. Pereira, L. Carvalho, J. A. Juanes-Méndez, and F. J. García-Peñalvo, "Learning with Mobile Technologies - Students' Behavior," Computers in Human Behavior, vol. 72, pp. 612-620, 2017. doi: 10.1016/j.chb.2016.05.027

[5] N. D. Azeez, and M. M. Lakulu, "Evaluation Framework of M-government Services Success in Malaysia," Journal of Theoretical and Applied Information Technology, vol. 96, no. 24, 2018.

[6] H. Peng, Y. J. Su, C. Chou, and C. C. Tsai, "Ubiquitous Knowledge Construction: Mobile Learning Re-Defined and A Conceptual Framework," Innovations in Education and Teaching International, vol. 46, no. 2, pp. 171-183, 2009. doi: 10.1080/14703290902843 828.

[7] N. M. Sabah, "Exploring Students' Awareness and Perceptions: Influencing Factors and Individual Differences Driving Mobile Learning Adoption," Computers in Human Behavior, vol. 65, pp. 522-533, 2016. doi: 10.1016/j.chb.2016.09.009.

[8] A. Kukulska-Hulme, "Will Mobile Learning Change Language Learning?," ReCALL, vol. 21, no. 2, pp. 157-165, 2009. doi: 10.1017/S0958344009000202.

[9] Y. Park," A Pedagogical Framework for Mobile Learning": Categorizing Educational Applications of Mobile Technologies into Four Types," The International Review of Research in Open and Distributed Learning, vol. 12, no. 2, pp. 78-102, 2011. doi: 10.3394/ 0380-1330, 2006)32.

[10] L. A. Mills, G. Knezek, and F. Khaddage, "Information Seeking, Information Sharing, and Going Mobile: Three Bridges to Informal Learning," Computers in Human Behavior, vol. 32, pp. 324-334, 2014. doi: 10.1016/j.chb.2013.08.008.

[11] I. I. Mahazir, M. N. Norazah, C. R. Ridzwan, and A. A. Azwin Arif, "Relationship between the Acceptance of Mobile Learning for AutoCAD Course and Learning Style in Polytechnic," Procedia - Social and Behavioral Sciences, 102(Ifee 2012), pp. 177-187, 2013. doi: 10.1016/j.sbspro.2013.10.731.

[12] R. A. Ali, and M. R. M. Arshad, "Understanding Intention to Use Mobile Learning: A Perspective of the Extended Unified Theory of Acceptance and Use of Technology," International Journal of Advanced and Applied Sciences, vol. 3, no. 7, pp. 81-88, 2016. doi: 10.21833/ijaas.2016. 07.013.

[13] V. Venkatesh, M. G. Morris, B. Davis, Gordon, and F. D. Davis, "User Acceptance of Information Technology: Toward A Unified View," MIS Quarterly, vol. 27, no. 3, pp. 425478. 2003.

[14] J. T. Marchewka and K. Kostiwa, "An Application of The UTAUT Model for Understanding Student Perceptions Using Course Management Software," Communications of the IIMA, vol. 7, no. 2, pp. 93-104, 2014.

[15] A. Abu-Al-Aish, and S. Love, "Factors Influencing Students' Acceptance of Mobile learning: An Investigation in Higher Education," The International Review of Research in Open and Distance Learning, vol. 14, no. 5, 2013.

[16] Y. U. Huan, X. Li, M. Aydeniz, and T. Wyatt, "Mobile Learning Adoption: An Empirical Investigation for Engineering Education," IJERT, 2018.

[17] H. Mohammadi, "Social and Individual Antecedents of Mobile Learning Adoption in Iran," Computers in Human Behavior, vol. 49, pp. 191-207, 2015. doi: 10.1016/j.chb.2015.03.006. 